\title{
Extensive proximal tubular necrosis without recovery following the ingestion of Amanita phalloides: a case report
}

\author{
Andrea Angioi ${ }^{1} \cdot$ Matteo Floris $^{1} \cdot$ Nicola Lepori $^{1} \cdot$ Paola Bianco $^{2} \cdot$ Gianfranca Cabiddu $^{1,3} \cdot$ Antonello Pani $^{1,3}$
}

Received: 13 October 2020 / Accepted: 2 March 2021 / Published online: 18 June 2021

(c) The Author(s) 2021

Keywords Amanitin $\cdot$ Amanita phalloides $\cdot$ Intoxication $\cdot$ Acute renal failure $\cdot$ Dialysis $\cdot$ Acute liverfailure

\section{Case description}

A 79-year-old Caucasian man and his wife were hospitalized in a peripheral hospital because of nausea, vomiting, watery diarrhea, and oliguria. Symptoms appeared $6 \mathrm{~h}$ after ingestion of about $200 \mathrm{~g}$ of cooked mushrooms (mistaken by the patient for Amanita caesarea and Boletus impolitus), foraged days before. In the emergency room, the standard protocol for mushroom poisoning was performed (gastric lavage, intravenous acetylcysteine: $150 \mathrm{mg} / \mathrm{kg}$ in $60 \mathrm{~min}$, and electrolyte replacement). Twenty-four hours after admission, he showed progressive decline of urine output and an abrupt increase of transaminases. He was therefore referred to our Division the following day, while his wife was discharged after $72 \mathrm{~h}$ of clinical observation. His past medical history showed type 2 diabetes with microvascular complications (diabetic retinopathy stage II), and hypertension being treated with angiotensin converting enzyme (ACE) inhibitors.

At admission, his vital parameters were normal (blood pressure [BP] 130/90 $\mathrm{mmHg}$, heart rate [HR] 82/m, body temperature $36.5^{\circ} \mathrm{C}$ ). Serum creatinine was $7.6 \mathrm{mg} / \mathrm{dl}$, blood urea nitrogen (BUN) $160 \mathrm{mg} / \mathrm{dl}$, with signs of acute liver and pancreas injury (aspartate aminotransferase [AST] $509 \mathrm{U} /$ $\mathrm{ml}$, alanine aminotransferase [ALT] 1,013 U/ml, total bilirubin $2.4 \mathrm{mg} / \mathrm{dl}$, amylase $566 \mathrm{U} / \mathrm{l}$, lipase $1402 \mathrm{U} / \mathrm{l}$, pancreatic amylase $525 \mathrm{U} / \mathrm{l})$. Urinalysis showed normal specific gravity

Antonello Pani

antonellopani@aob.it

1 Division of Nephrology, Dialysis and Transplantation "San Michele" Hospital, ARNAS G. Brotzu, Cagliari, Italy

2 Pathology Service, "San Michele" Hospital, ARNAS G. Brotzu, Cagliari, Italy

3 Department of Medical Science and Public Health, University of Cagliari, ARNAS G. Brotzu, Cagliari, Italy
(1.012), glycosuria (50 mg/dl), and mild proteinuria (50 mg/ $\mathrm{dl})$, while urinary sediment displayed several granular casts with mild hematuria (16 red cells/HPF). Urinary amatoxin (alpha amanitin) was positive, confirming the diagnosis; interestingly, the toxin was still detected in the urine as late as 14 days after poisoning. Renal ultrasound showed kidneys of normal size, with hyperechoic parenchyma.

Intravenous acetylcysteine was continued until his liver parameters improved; dialysis was started with sustained low-efficiency daily diafiltration (SLEDD-f) in an attempt to reduce amatoxin concentration. In view of the lack of kidney function recovery, the patient was later switched to standard hemodialysis. To explore the causes of this persistent kidney failure, we performed a kidney biopsy that showed severe, diffuse, acute tubular necrosis, consistent with the clinical suspicion of amatoxin toxicity superimposed on diabetic nephropathy (Figs. 1 and 2).

The patient was discharged on chronic hemodialysis and five years later he is still undergoing dialysis with no signs of chronic liver disease.

\section{Lesson for the clinical nephrologist}

Amanita phalloides (also called "deathcap") is a basidiomycete fungus of the genus Amanita known by foragers and clinicians to be a potential cause of fatal acute liver injury. Among food poisoning cases in the US, Amanita phalloides accounts for more than $90 \%$ of fatalities, with an estimated mortality of 50\% in adults and $33 \%$ in children in a dated series [1]. In the absence of up-to-date, high quality evidence, it is legitimate to assume that survival has considerably improved thanks to progress in supportive care and liver transplant $[2,3]$. 
Amanita phalloides produces two types of toxins that cause the phalloideal syndrome: amatoxins and phallotoxins. In humans, phallotoxins exert a direct influence on the cytoskeleton, thus causing a mild and transient enteric syndrome within 6-24 $\mathrm{h}$ from ingestion, while amatoxins (in particular alpha amanitin) tightly inhibit RNA polymerase II in the hepatocytes. The impairment of synthetic activity and the loss of structural proteins cause hepatocyte necrosis, which manifests as severe, often fatal, acute liver failure. Kidney failure and anuria are initially the result of dehydration but subsequently kidney damage may be the expression of direct alpha amanitin toxicity to the proximal tubular cells.

As a general rule, once the liver injury is resolved, the renal tubular epithelium progressively regenerates, leading to complete or partial recovery of kidney function [3, 4]. End-stage kidney disease with the need for definitive renal replacement therapy has been described [5]; however, in this condition, renal histology has seldom been reported $[6,7]$.

Why this patient developed end-stage kidney disease is unclear. Our patient had additional risk factors: type 2 diabetes, hypertension, and a previously known chronic kidney disease. Indeed, although not quantitated, we observed traces of alpha amanitin in the urine 14 days after ingestion, suggesting a relevant toxin load; whether the loss of kidney function is dose-related or independent is not known. It is also reasonable to assume that age, which increases the risk of developing comorbidities, has an impact on the renal and overall outcomes.

In animal models of poisoning by Amanita phalloides, the histological pattern is that of acute tubular necrosis and reactive interstitial nephritis [8]. In our patient, interstitial inflammation was mild, with focal tubulitis and mild interstitial edema, and there were foci of regenerating tubular epithelium, which led us to assume there would be prompt recovery. We were unable to precisely determine the prognosis because (1) how to determine the extent to which tissue has undergone irreversible functional injury after severe acute tubular toxicity is not known; (2) the prognostic value of tissue regeneration on kidney histology is misleading; (3) we do not know what the real proliferating capacity of tubular cells with chronic kidney disease in the background is.

Despite all the measures undertaken to reduce the toxic load as per the current literature data (Table 1), and taking into consideration the pre-existing $\mathrm{CKD}$, prolonged

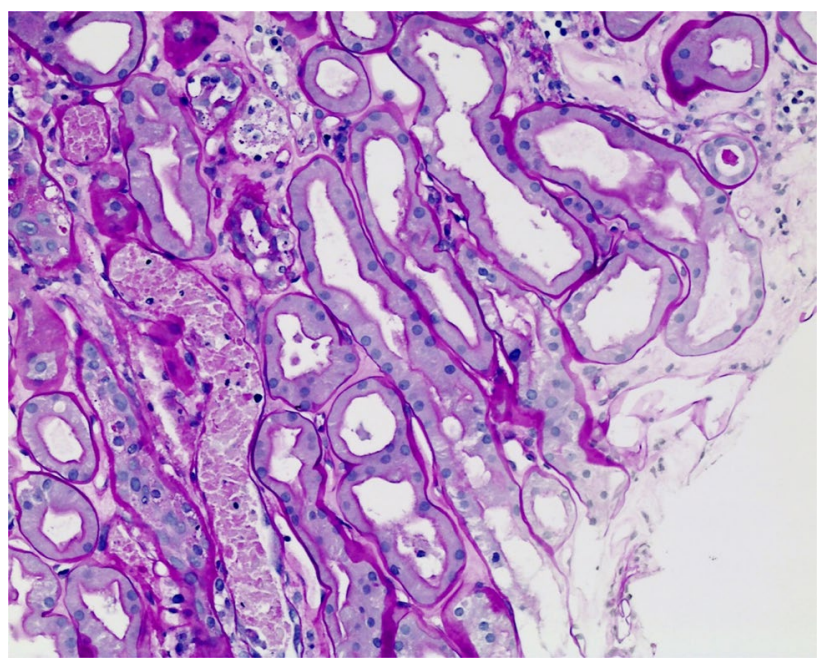

Fig. 1 Acute tubular necrosis with granular casts containing nuclear fragments and eosinophilic cytoplasmic debris derived from necrotic tubular epithelial cells (PAS, 100×)

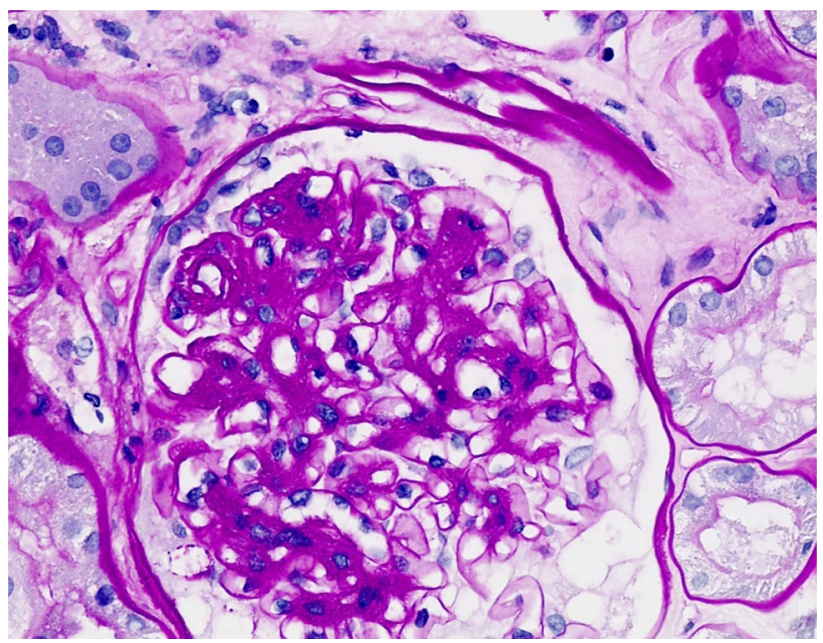

Fig. 2 Marked global expansion of the mesangial matrix and cellularity with segmental capillary loop adhesions to Bowman's capsule. (PAS, 200×)

toxicity may explain the dissociation between liver recovery and kidney failure.

Our case points out the importance of considering mushroom poisoning as a potential cause of acute liver and kidney failure and highlights the fact that, especially 


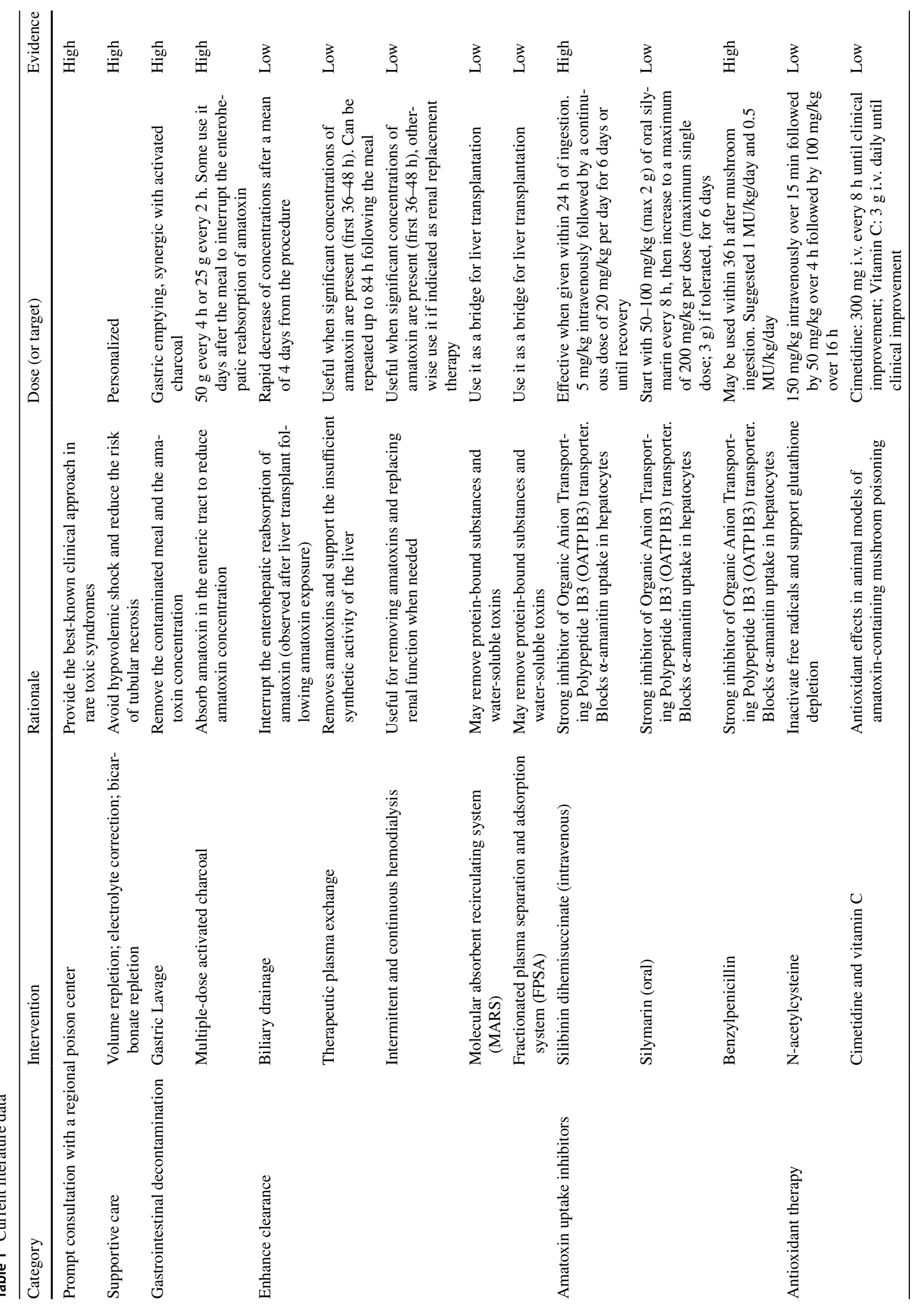




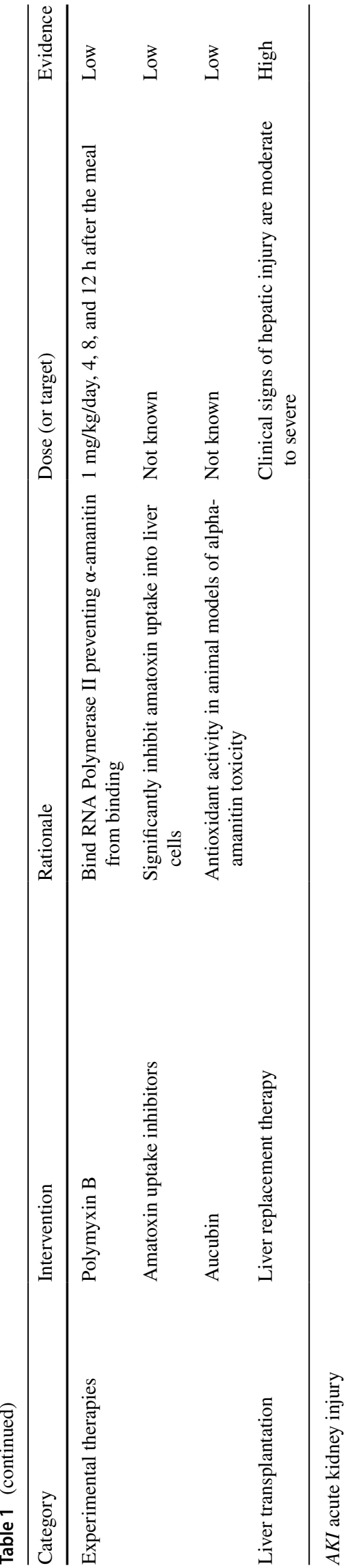

in subjects with a pre-existing kidney disease (hypertension, diabetes), renal failure may be irreversible.

Acknowledgements Andrea Angioi, Matteo Floris and Nicola Lepori contributed equally to the preparation of this paper

\section{Compliance with ethical standard}

Conflict of interest On behalf of all authors, the corresponding author states that there is no conflict of interest.

Ethical approval This article does not contain any studies with human participants performedby any of the authors.

Open Access This article is licensed under a Creative Commons Attribution 4.0 International License, which permits use, sharing, adaptation, distribution and reproduction in any medium or format, as long as you give appropriate credit to the original author(s) and the source, provide a link to the Creative Commons licence, and indicate if changes were made. The images or other third party material in this article are included in the article's Creative Commons licence, unless indicated otherwise in a credit line to the material. If material is not included in the article's Creative Commons licence and your intended use is not permitted by statutory regulation or exceeds the permitted use, you will need to obtain permission directly from the copyright holder. To view a copy of this licence, visit http://creativecommons.org/licenses/by/4.0/.

\section{References}

1. Jaeger A, Jehl F, Flesch F, Sauder P, Kopferschmitt J (1993) Kinetics of amatoxins in human poisoning: therapeutic implications. J Toxicol Clin Toxicol 31(1):63-80

2. Pond SM, Olson KR, Woo OF, Osterloh JD, Ward RE, Kaufman DA, Moody RR (1986) Amatoxin poisoning in northern California, 1982-1983. West J Med 145(2):204-209

3. Krenova M, Pelclova D, Navratil T (2007) Survey of Amanita phalloides poisoning: clinical findings and follow-up evaluation. Hum Exp Toxicol 26(12):955-961

4. Leathem AM, Purssell RA, Chan VR, Kroeger PD (1997) Renal failure caused by mushroom poisoning. J Toxicol Clin Toxicol 35(1):67-75

5. Unverir P, Soner BC, Dedeoglu E, Karcioglu O, Boztok K, Tuncok Y (2007) Renal and hepatic injury with elevated cardiac enzymes in Amanita phalloides poisoning: a case report. Hum Exp Toxicol 26(9):757-761

6. Fineschi V, Di Paolo M, Centini F (1996) Histological criteria for diagnosis of amanita phalloides poisoning. J Forensic Sci 41(3):429-432

7. Garrouste C, Hemery M, Boudat AM, Kamar N (2009) Amanita phalloides poisoning-induced end-stage renal failure. Clin Nephrol 71(5):571-574

8. Garcia J, Costa VM, Carvalho AT, Silvestre R, Duarte JA, Dourado DF, Arbo MD, Baltazar T, Dinis-Oliveira RJ, Baptista P et al (2015) A breakthrough on Amanita phalloides poisoning: an effective antidotal effect by polymyxin B. Arch Toxicol 89(12):2305-2323

Publisher's Note Springer Nature remains neutral with regard to jurisdictional claims in published maps and institutional affiliations. 